\title{
Efficacy and Safety of Voglibose Plus Metformin in Patients with Type 2 Diabetes Mellitus: A Randomized Controlled Trial (Diabetes Metab J 2019;43;276-86)
}

\author{
Hannah Seok, Tae Seo Sohn \\ Department of Internal Medicine, College of Medicine, The Catholic University of Korea, Seoul, Korea
}

The proportion of people with type 2 diabetes mellitus (T2DM) is increasing in most countries, and the estimated population of diabetes in Korean adults ( $\geq 30$ years of age) is 4.8 million, which represented $13.7 \%$ of Korean adults ( $\geq 30$ years of age) in 2013 to 2014 [1]. Because the complications of T2DM are related to glycemic level, glycemic control to achieve normoglycemia or near-normoglycemia reduces the risk of cardiovascular and/or microvascular complications [2]. The treatment goals should be individualized considering age, duration of diabetes, life expectancy, presence of advanced diabetic complications, comorbidities, repeated episodes of hypoglycemia, cognitive dysfunction, and patient preference. Medical nutrition therapy and exercise is an essential component of treatment for all patients with T2DM and should be initiated promptly and simultaneously with antidiabetic medications after diagnosis. Metformin is the first-line drug that is used for the treatment of T2DM worldwide. If the initial glycosylated hemoglobin (HbA1c) level of a patient is $\geq 7.5 \%$ or the HbAlc target is not achieved within 3 months initiating monotherapy, dual combination therapy can be considered. The early initiation of combination therapy is preferred over maximizing the dosage of a single agent after considering glucose-lowering efficacy and side-effects [3].

Alpha-glucosidase inhibitor (AGI) acts as a competitive inhibitor of enzymes needed to digest carbohydrates and reduces postprandial glucose level by lowering carbohydrate absorp- tion, but it also causes gastrointestinal (GI) side-effects such as flatulence and diarrhea. Therefore, adding AGI to metformin could be useful for glycemic control, especially in East Asian countries that consume relatively high-carbohydrate diets.

In this issue, Oh et al. [4] report the study entitled "Efficacy and safety of voglibose plus metformin in patients with type 2 diabetes mellitus: a randomized controlled trial," which showed the effectiveness and safety of voglibose-metformin fixed-dose combination (vogmet) in drug-naïve, newly diagnosed T2DM patients. In this study, vogmet treatment showed higher HbA1c reduction, lower glycemic variability, lower gastrointestinal (GI) adverse events (AEs), and higher weight loss than metformin monotherapy. Patients received metformin (500 mg) or vogmet $(0.2 / 250$ or $0.2 / 500 \mathrm{mg})$ two or three times a day. Although the final dosage of metformin was slightly higher in metformin group than vogmet group $(1,322.4 \pm 166.1 \mathrm{mg}$ vs. $1,208.8 \pm 263.1 \mathrm{mg}, P<0.001)$, it is interesting that the vogmet group showed numerically less GI AE and significantly higher weight loss than metformin group. In terms of body weight, AGI is known to have a neutral effect, and metformin has a neutral or reducing effect [3]. Both metformin and AGI have does-dependent GI side-effects [5], and these side-effects are one of the largest barriers in choosing metformin or voglibose in clinical practice. The diet pattern and glucose-lowering effects and side-effects according to drug dose in vogmet group could give more information about voglibose and metformin
Corresponding author: Tae Seo Sohn (iD https://orcid.org/0000-0002-5135-3290 Department of Internal Medicine, Uijeongbu St. Mary's Hospital, College of Medicine, The Catholic University of Korea, 271 Cheonbo-ro, Uijeongbu 11765, Korea E-mail: imsts@catholic.ac.kr
This is an Open Access article distributed under the terms of the Creative Commons Attribution Non-Commercial License (http://creativecommons.org/licenses/by-nc/4.0/) which permits unrestricted non-commercial use, distribution, and reproduction in any medium, provided the original work is properly cited. 
treatment.

In this study, M-value by 7-points self-monitored blood glucose (SMBG) was used to investigate glycemic variability. However, SMBG may not be sufficient to evaluate glucose fluctuation like inter-day difference or intra-day difference [6,7]. Continuous glucose monitoring could be a better option for evaluation of glucose fluctuation.

Lastly, it might be better if they evaluate the effect of vogmet on waist circumference, blood pressure, lipid profiles, the homeostasis model assessment of $\beta$-cell, and insulin resistance.

Korean Diabetes Association recommends that the selection of a second agent as a metformin add-on therapy should be based on the patient's clinical characteristics and the efficacy, side effects, mechanism of action, risk of hypoglycemia, effect on body weight, patient preference, and combined comorbidity [8]. In this aspect, AGI could be a good choice as a secondline therapy in some patients with T2DM.

\section{CONFLICTS OF INTEREST}

No potential conflict of interest relevant to this article was reported.

\section{REFERENCES}

1. Won JC, Lee JH, Kim JH, Kang ES, Won KC, Kim DJ, Lee MK. Diabetes fact sheet in Korea, 2016: an appraisal of current status. Diabetes Metab J 2018;42:415-24.

2. UK Prospective Diabetes Study (UKPDS) Group. Intensive blood-glucose control with sulphonylureas or insulin compared with conventional treatment and risk of complications in patients with type 2 diabetes (UKPDS 33). Lancet 1998;352: 837-53.

3. Ko SH, Hur KY, Rhee SY, Kim NH, Moon MK, Park SO, Lee BW, Kim HJ, Choi KM, Kim JH; Committee of Clinical Practice Guideline of Korean Diabetes Association. Antihyperglycemic agent therapy for adult patients with type 2 diabetes mellitus 2017: a position statement of the Korean Diabetes Association. Diabetes Metab J 2017;41:337-48.

4. Oh TJ, Yu JM, Min KW, Son HS, Lee MK, Yoon KH, Song YD, Park JY, Jeong IK, Cha BS, Kim YS, Baik SH, Kim IJ, Kim DM, Kim SR, Lee KW, Park JH, Lee IK, Park TS, Choi SH, Park SW. Efficacy and safety of voglibose plus metformin in patients with type 2 diabetes mellitus: a randomized controlled trial. Diabetes Metab J 2019;43:276-86.

5. van de Laar FA, Lucassen PL, Akkermans RP, van de Lisdonk EH, Rutten GE, van Weel C. Alpha-glucosidase inhibitors for patients with type 2 diabetes: results from a Cochrane systematic review and meta-analysis. Diabetes Care 2005;28:154-63.

6. Service FJ. Glucose variability. Diabetes 2013;62:1398-404.

7. Suh S, Kim JH. Glycemic variability: how do we measure it and why is it important? Diabetes Metab J 2015;39:273-82.

8. Moon MK, Hur KY, Ko SH, Park SO, Lee BW, Kim JH, Rhee SY, Kim HJ, Choi KM, Kim NH; Committee of Clinical Practice Guidelines of the Korean Diabetes Association. Combination therapy of oral hypoglycemic agents in patients with type 2 diabetes mellitus. Diabetes Metab J 2017;41:357-66. 